\title{
Phosphate-dependent regulation of the low- and high-affinity transport systems in the model actinomycete Streptomyces coelicolor
}

\author{
Correspondence \\ Juan F. Martín \\ jf.martin@unileon.es
}

Received 11 April 2008

Accepted 27 April 2008

\author{
Fernando Santos-Beneit, ${ }^{1}$ Antonio Rodríguez-García, ${ }^{1}$ \\ Etelvina Franco-Domínguez ${ }^{1}$ and Juan F. Martín ${ }^{1,2}$ \\ ${ }^{1}$ Instituto de Biotecnología de León, INBIOTEC, Parque Científico de León, Av. Real, 1, \\ 24006 León, Spain \\ ${ }^{2}$ Área de Microbiología, Fac. CC. Biológicas y Ambientales, Universidad de León, Campus de
Vegazana, s/n, 24071 León, Spain
}

\begin{abstract}
The transport of inorganic phosphate $\left(\mathrm{P}_{\mathrm{i}}\right)$ is essential for the growth of all organisms. The metabolism of soil-dwelling Streptomyces species, and their ability to produce antibiotics and other secondary metabolites, are strongly influenced by the availability of phosphate. The transcriptional regulation of the SCO4138 and SCO1845 genes of Streptomyces coelicolor was studied. These genes encode the two putative low-affinity $\mathrm{P}_{\mathrm{i}}$ transporters $\mathrm{PitH} 1$ and $\mathrm{PitH} 2$, respectively. Expression of these genes and that of the high-affinity transport system pstSCAB follows a sequential pattern in response to phosphate deprivation, as shown by coupling their promoters to a luciferase reporter gene. Expression of pitH2, but not that of pap-pitH1 (a bicistronic transcript), is dependent upon the response regulator PhoP. PhoP binds to specific sequences consisting of direct repeats of $11 \mathrm{nt}$ in the promoter of pitH2, but does not bind to the pap-pitH1 promoter, which lacks these direct repeats for PhoP recognition. The transcription start point of the pitH2 promoter was identified by primer extension analyses, and the structure of the regulatory sequences in the PhoP-protected DNA region was established. It consists of four central direct repeats flanked by two other less conserved repeats. A model for PhoP regulation of this promoter is proposed based on the four promoter DNA-PhoP complexes detected by electrophoretic mobility shift assays and footprinting studies.
\end{abstract}

\section{INTRODUCTION}

Streptomyces are soil-dwelling Gram-positive filamentous bacteria with complex regulatory networks that allow their adaptation to changing nutritional conditions (Chater \& Bibb, 1997). Streptomyces species have a central role in soil ecology processes, and produce an impressive array of secondary metabolites with interesting biological properties and pharmacological activities (Bérdy, 2005). There are hundreds of genes in the sequenced genomes of Streptomyces that encode enzymes for the biosynthesis of secondary metabolites (Omura et al., 2001; Bentley et al., 2002). The biosynthesis of most secondary metabolites is negatively regulated by phosphate (Martín et al., 1994).

Phosphorus is an essential component of bacterial nutrition and is one of the major constituents of the cell, making up $\sim 1.5-2.1 \%$ of the cell dry weight. Phosphorus plays an important role in cell metabolism and is a

Abbreviations: DRu, direct repeat unit; EMSA, electrophoretic mobility shift assay; Ri, information content; TMS, transmembrane segment; TSP, transcription start point. constituent of nucleic acids, phospholipids, phosphatecontaining lipopolysaccharides, nucleotide cofactors and some post-translationally modified proteins.

Expression of phosphate-regulated genes in Streptomyces species is modulated by the two-component system PhoRPhoP (Sola-Landa et al., 2003). PhoR is the membrane sensor kinase, and senses phosphate scarcity; PhoP is the response regulator, and binds DNA and controls the transcription of genes belonging to the so-called $\mathrm{PHO}$ regulon. PhoP has been shown to modulate the expression of primary and secondary metabolism genes, including the actinorhodin and undecylprodigiosin biosynthesis genes (Sola-Landa et al., 2003; Ghorbel et al., 2006). Binding of PhoP to the promoter regions of three different genes of the PHO regulon, pstS, phoU and phoRP, has been shown in both Streptomyces coelicolor (Sola-Landa et al., 2005) and Streptomyces natalensis (Mendes et al., 2007). The PhoP operator sequences of these genes, as well as those present in the promoter regions of phoA and phoD of S. coelicolor (Apel et al., 2007), are composed of direct repeat units (DRus) of $11 \mathrm{nt}$. Novel operator sequences have been 
recently described in S. coelicolor (Sola-Landa et al., 2008). Analysis of the novel and the previously known operators (up to 19) by means of electrophoretic mobility shift assays (EMSAs), footprinting, and information theory studies, has revealed the structure of the PhoP-binding sites. Two or three well-conserved DRus form the core of the binding site, in which each DRu is bound by a protein monomer. Complex sites have adjacent DRus that are bound subsequently (Sola-Landa et al., 2008).

The transport of phosphorus sources is essential for the growth of all living organisms. The preferred source of phosphorus in bacteria is inorganic phosphate $\left(\mathrm{P}_{\mathrm{i}}\right)$, which can enter the cell with the aid of at least two different transport systems (as described below), although there are other phosphorus-containing compounds that can enter the cell intact, such as organophosphates and phosphonates. However, numerous organic phosphate compounds have to be hydrolysed before being transported into the cell, such as nucleotides, some sugar phosphates, and phospholipids (Martín \& Demain, 1977, 1980). S. coelicolor and other Streptomyces species contain at least three phosphatases and a phosphodiesterase system (Apel et al., 2007) to hydrolyse different organic phosphates.

$\mathrm{P}_{\mathrm{i}}$ is taken up in bacteria mainly by two different transport systems, the high-affinity phosphate-specific transporter (Pst) and the low-affinity phosphate inorganic transporter (Pit). Pst is an ABC transporter that has an ATP-driven high-affinity $\mathrm{P}_{\mathrm{i}}$ uptake. In Escherichia coli this transporter is composed of four proteins. These are the PstS (periplasmic phosphate-binding), PstA and PstC (integral membrane proteins), and PstB (ATP-binding) subunits. The pstSCAB operon belongs to the $\mathrm{PHO}$ regulon and has been identified in E. coli and in other bacterial species (Rao \& Torriani, 1990; Nikata et al., 1996). The pstS gene has also been studied in S. coelicolor (Sola-Landa et al., 2005; Díaz et al., 2005), in which its expression is subject to a strict phosphate control.

Pit is a low-affinity, high-velocity phosphate-uptake system and is dependent on the proton motive force for energy. The Pit transport system has been studied in E. coli (Hoffer et al., 2001; Harris et al., 2001; van Veen et al., 1994a; van Veen, 1997), Acinetobacter johnsonii (van Veen et al., 1993, 1994b, c; van Veen, 1997) and Sinorhizobium meliloti (Voegele et al., 1997; Bardin \& Finan, 1998; Bardin et al., 1998; Yuan et al., 2006a). In E. coli, Pit is the major $\mathrm{P}_{\mathrm{i}}$ uptake system when $P_{i}$ is in excess (Rosenberg et al., 1977, 1979) and consists of a single transmembrane protein (Elvin et al., 1986). Divalent cations such $\mathrm{Mg}^{2+}$ and $\mathrm{Ca}^{2+}$ are essential for Pit activity in both E. coli (Russell \& Rosenberg, 1980) and A. johnsonni (van Veen et al., 1994b), since phosphate is symported with a proton, as a soluble and neutral metal complex $\left(\mathrm{MeHPO}_{4}\right.$; van Veen et al., 1994a, c; van Veen, 1997).

E. coli contains two functional pit genes, pitA and pitB (Hoffer et al., 2001; Harris et al., 2001). Two or more paralogues can also be found in many other genomes. PitA and PitB have similar transport characteristics (Hoffer et al., 2001) and have $90 \%$ similar amino acid sequences. However, the regulation of the two genes appears to be different. Thus, pitA is expressed constitutively, while pit $B$ appears to be repressed under conditions of phosphate limitation (Elvin et al., 1986; Harris et al., 2001).

The pit gene(s) have not been studied in Streptomyces species, but their characterization is important to establish their role in phosphate transport and their effect on the biosynthesis of secondary metabolites and on the ecology of these bacteria in soil. This work describes two paralogous pit genes in S. coelicolor, and elucidates their pattern of regulation by means of both in vivo assays, using wild-type $S$. coelicolor and $\triangle p h o P$ mutant strains, and DNA-binding PhoP-footprinting analysis.

\section{METHODS}

Bacterial strains and plasmids. The bacterial strains and plasmids used in this work are listed in Table 1. S. coelicolor strains M145 (Kieser et al., 2000) and INB101 ( $\Delta p h o P)$ (Rodríguez-García et al., 2007) were manipulated according to standard procedures (Kieser et al., 2000). TBO medium (Higgens et al., 1974) was used to obtain spore preparations. E. coli DH5 $\alpha$ was the general cloning host. Cloning procedures were performed as described by Sambrook et al. (1989).

The pap-pitH1 and pitH2 promoter regions were amplified by PCR using total DNA as template, as follows. The primers FSC21 (5'TGGTGGATCCCGCGTCCTCCAATAACGG) and FSC22 (5'CAGAGGTACCATATGGTGGGGTCCTCGGGGTGCATGGGTTTC) amplified a $232 \mathrm{bp}$ fragment encompassing the promoter region of pap-pitH1 from -210 to -3 (positions from the ATG translation start triplet). The BamHI (FSC21) and KpnI/NdeI (FSC22) cloning sites (underlined) were introduced via the primer sequences. Primers FSC15 (5'-CTTCGGATCCTCCGGCCCGCGAATAC) and FSC16 (5'-GAGAGGTACCATATGTACCCAGGCAATCGTTCG) were used to amplify a $270 \mathrm{bp}$ fragment encompassing the promoter region of pitH2 from positions -250 to -3 (positions from the translation start) flanked by the above-mentioned cloning sites. BamHI-KpnI fragments were cloned into pBluescript II SK + to obtain pFS-pitH1 and pFS-pitH2, respectively. The inserts of both plasmids were checked by sequencing.

The $p s t S$ promoter region was cloned from pGEM-P pstS (Sola-Landa et al., 2005). BamHI-NdeI fragments of 222 bp from pFS-pitH1, $260 \mathrm{bp}$ from pFS-pitH2, and $403 \mathrm{bp}$ from pGEM-P pstS were cloned into the promoter-probe vector pLUXAR + (Rodríguez-García et al., 2007), yielding pLUX-pitH1, pLUX-pitH2 and pLUX-pstS, respectively. In order to introduce the pLUX plasmids into the $S$. coelicolor INB101 strain (which is apramycin resistant), the neo gene was inserted to construct derivatives with neomycin resistance (Table 1).

Culture conditions. S. coelicolor cultures were performed in defined MG (maltose and glutamate) medium containing starch (Scharlau; $\left.50 \mathrm{~g}^{-1}\right)$ and glutamate $(60 \mathrm{mM})$ (Doull \& Vining, 1989). Aliquots $(100 \mathrm{ml})$ of MG medium in $500 \mathrm{ml}$ baffled flasks were inoculated with $10^{6}$ spores $\mathrm{ml}^{-1}$ and incubated at $30{ }^{\circ} \mathrm{C}, 300$ r.p.m. $(25.4 \mathrm{~mm}$ orbit diameter) for reproducible and dispersed growth. For the phosphate-replete and the phosphate-limited conditions, cultures contained 18.5 and $3.2 \mathrm{mM}$ potassium phosphate, respectively (MG18.5 and MG-3.2 media; experimentally determined concentrations). The potassium concentrations in MG-18.5 and MG-3.2 were equalized by adding $\mathrm{KOH}$ to $\mathrm{MG}-3.2$, instead of $\mathrm{NaOH}$ alone, when 
Table 1. Bacterial strains and plasmids used in this work

\begin{tabular}{|c|c|c|}
\hline Strain or plasmid & Characteristics & Reference or source \\
\hline \multicolumn{3}{|l|}{ Strains } \\
\hline S. coelicolor A3(2) M145 & Wild-type & Kieser et al. (2000) \\
\hline S. coelicolor A3(2) INB101 & $\Delta p h o P, \mathrm{Am}^{\mathrm{r}}$ & Rodríguez-García et al. (2007) \\
\hline E. coli $\mathrm{DH} 5 \alpha$ & $\mathrm{F}^{\prime} \Phi 80 d L a c Z \Delta \mathrm{M} 15$ & Hanahan (1983) \\
\hline E. coli ET12567 (pUZ8002) & dam dcm mutant, $\mathrm{Neo}^{\mathrm{r}}-\mathrm{Cm}^{\mathrm{r}}$ & MacNeil et al. (1992) \\
\hline \multicolumn{3}{|l|}{ Plasmids } \\
\hline pBluescript II SK+ & Cloning vector, $\mathrm{Amp}^{\mathrm{r}}$ & Stratagene \\
\hline pFS-pitH1 & $\begin{array}{l}\text { PCR product carrying pitH1 promoter cloned into pBluescript II } \\
\mathrm{SK}+, \mathrm{Amp}^{\mathrm{r}}\end{array}$ & This work \\
\hline pFS-pitH2 & $\begin{array}{l}\text { PCR product carrying pitH2 promoter cloned into pBluescript II } \\
\text { SK }+, \mathrm{Amp}^{\mathrm{r}}\end{array}$ & This work \\
\hline pLUXAR + & Integrative promoter-probe vector, $\operatorname{lu} x A B$ genes, $A m^{r}$ & Rodríguez-García et al. (2007) \\
\hline pLUX-pitH1 & BamHI-NdeI pFS-pitH1 fragment cloned into pLUXAR,$+ \mathrm{Am}^{\mathrm{r}}$ & This work \\
\hline pLUX-pitH2 & BamHI-NdeI pFS-pitH2 fragment cloned into pLUXAR,$+ \mathrm{Am}^{\mathrm{r}}$ & This work \\
\hline pLUX-pstS & BamHI-NdeI pGEM-PpstS fragment cloned into pLUXAR,$+ \mathrm{Am}^{\mathrm{r}}$ & This work \\
\hline pLUX-pitH1-Neo & pLUX-pitH1 with the neo gene inserted, $\mathrm{Am}^{\mathrm{r}}-\mathrm{Neo}^{\mathrm{r}}$ & This work \\
\hline pLUX-pitH2-Neo & pLUX-pitH2 with the neo gene inserted, $\mathrm{Am}^{\mathrm{r}}-\mathrm{Neo}^{\mathrm{r}}$ & This work \\
\hline
\end{tabular}

the $\mathrm{pH}$ was adjusted (sodium ions in both media are in excess, $\sim 60$ $75 \mathrm{mM}$ ). Samples were taken after 36, 40, 44, 48, 60, 70 and $90 \mathrm{~h}$ of incubation.

Luciferase assay, and growth and phosphate determination. lux $A B$ gene expression was determined in a Luminoskan luminometer (Labsystems). Culture samples $(1 \mathrm{ml})$ were taken, spun down $\left(4{ }^{\circ} \mathrm{C}\right.$, $10 \mathrm{~min}$ ) and kept frozen until all samples from an experiment were available to be processed simultaneously; then the cells were resuspended in $1 \mathrm{ml} \mathrm{NaCl}\left(0.9 \%\right.$, w/v), incubated at $25{ }^{\circ} \mathrm{C}$ for $15 \mathrm{~min}$ and measured in triplicate, as described in Rodríguez-García et al. (2007).

For dry weight determination, culture samples $(2 \mathrm{ml})$ were washed twice with MilliQ water and dried for 4 days at $80{ }^{\circ} \mathrm{C}$.

The phosphate concentration of MG medium and culture supernatants was measured using the malachite green assay (Lanzetta et al., 1979).

RT-PCR. RNAs from $S$. coelicolor wild-type and $\triangle p h o P$ strains were isolated using RNeasy Mini Spin columns (Qiagen). Before RNA isolation, one volume of each culture was treated with two volumes of RNAProtect Bacteria reagent (Qiagen) to provide immediate stabilization of RNA. Cell lysis and phenol pre-purification were carried out prior to column purification as described previously (Rodríguez-García et al., 2007). RNA preparations were treated oncolumn with DNase I (Qiagen), and the eluted solution with the DNA-free kit (Ambion) to eliminate possible chromosomal DNA contamination. RNA concentration and quality were checked using a NanoDrop ND-1000 (Thermo Fisher Scientific) and RNA nano labchips in a 2100 Bioanalyser (Agilent).

Gene expression analysis by RT-PCR was performed with the SuperScript One-Step RT-PCR system with Platinum Taq (Invitrogen). Primers CAR65 (5'-ATTTCACGAACGGTTTCCAC) and CAR66 (5'-GATGCCCATGGTCTTCTGG) were used to amplify 542 bp of the pitH2 coding region; primers CAR67 (5'-CGTACACCAACGGTTTCCAC) and CAR68 (5'-ATGCCCATCGTCTTCTGC) were used to amplify $541 \mathrm{bp}$ of pitH1. The synthesis of a common transcript pap-pitH1 was detected with the primer pair CAR73 (5'-ACCGCGAGGACATCTACAAC) and CAR74 (5'ACCAGGTGATGAGGTTCCAG). RT-PCR cycling conditions were as follows: $50{ }^{\circ} \mathrm{C}$ for $60 \mathrm{~min}, 94{ }^{\circ} \mathrm{C}$ for $2 \mathrm{~min}$; 11 cycles of $94{ }^{\circ} \mathrm{C}$ for $30 \mathrm{~s}, 65{ }^{\circ} \mathrm{C}$ for $30 \mathrm{~s}$ with touchdown of $1{ }^{\circ} \mathrm{C}$ per cycle, $72{ }^{\circ} \mathrm{C}$ for $60 \mathrm{~s}$; 23-29 cycles of $94{ }^{\circ} \mathrm{C}$ for $30 \mathrm{~s}, 55{ }^{\circ} \mathrm{C}$ for $30 \mathrm{~s}, 72{ }^{\circ} \mathrm{C}$ for $40 \mathrm{~s}$; finally $72{ }^{\circ} \mathrm{C}$ for $10 \mathrm{~min}$. Total RNA (200 ng), $1.6 \mathrm{mM} \mathrm{MgSO}_{4}$ (final concentration), and $5 \%$ DMSO were added in all reactions. Platinum Taq was used in the control reactions to check for the absence of DNA contamination.

DNA-protein binding assays. DNA-binding analyses were performed by EMSA with the GST-PhoP ${ }^{\text {DBD }}$ protein (PhoP DNAbinding domain fused to glutathione-S-transferase), as described previously (Sola-Landa et al., 2005). The probes used were the BamHI-KpnI fragments of 222 and 260 bp obtained by PCR of the promoter regions of pap-pitH1 and pitH2 and purified after agarosegel electrophoresis (GFX columns; GE Healthcare). Probes were labelled at both ends with DIG (DIG Oligonucleotide 3'-End Labeling kit, Roche Applied Science).

DNase I footprinting assays. DNase I footprinting assays based on the fluorescent label procedure (Rodríguez-García et al., 1997) were performed as described in Sola-Landa et al. (2005). DNA probes were obtained by PCR using pFS-pitH2 as template. For analysis of the coding strand, a fluorescently-labelled universal primer and a nonlabelled reverse primer were used; for the complementary strand, the labelled primer was the reverse primer. The labelled probes (424 and $419 \mathrm{bp}$ for the coding and complementary strand, respectively) were purified by agarose electrophoresis (GFX columns). DNase I footprinting was performed by incubating $0.28 \mathrm{pmol}$ of the DNA probe with different concentrations of GST-PhoP ${ }^{\mathrm{DBD}}$ protein for $30 \mathrm{~min}$ at $30{ }^{\circ} \mathrm{C}$. Nuclease digestions were carried out for $1 \mathrm{~min}$ at $30{ }^{\circ} \mathrm{C}$. The reaction products were resolved in an ALF DNA sequencer (GE Healthcare) and analysed with the Fragment Manager program.

Primer extension analysis. For primer extension analysis, RNA samples were isolated as described above, but with the RNeasy Midi kit (Qiagen) and the on-column DNase treatment only. Total RNA concentration and quality were checked both spectrophotometrically and by denaturing agarose gel electrophoresis. Transcription start sites were determined by the fluorescent primer extension procedure (Altermann et al., 1999; Fekete et al., 2003), modified as follows. Primers LUX-FAM + 47 [6-carboxyfluorescein- (6-FAM) 5' 
GATAGCTCAGGTGGCTGATAAG] and LUX-FAM + 135 (6-FAM 5'-GTGGTGCTCTAGCAACCAAAC), both obtained from MWGBiotech, were complementary to the coding region of luxAB genes of the pLUXAR + vector (nucleotides +25 to +47 and +114 to +135 with respect to the translation start, respectively). These primers (20$40 \mathrm{pmol})$ were hybridized with total RNA $(20-30 \mu \mathrm{g})$ in a $10 \mu \mathrm{l}$ final volume by heating to $90{ }^{\circ} \mathrm{C}$ for $2 \mathrm{~min}$ and cooling to $30{ }^{\circ} \mathrm{C}$ at a rate of $2{ }^{\circ} \mathrm{C} \mathrm{min}{ }^{-1}$. Then, cDNA synthesis was performed with either Superscript II or Superscript III reverse transcriptase (Invitrogen). The primer extension reaction $(30 \mu \mathrm{l})$ contained $10 \mathrm{mM}$ DTT, $500 \mu \mathrm{M}$ dNTPs (NEB), $1.5 \mu \mathrm{g}$ actinomycin D, $10 \mathrm{U}$ SUPERase-In (RNase inhibitor; Ambion), and $200 \mathrm{U}$ reverse transcriptase in $1 \times$ First Strand buffer (Invitrogen). The samples were incubated at $42{ }^{\circ} \mathrm{C}$ for 5 or $15 \mathrm{~h}$. Then, $10 \mu \mathrm{l} \mathrm{NaOH}(1 \mathrm{M})$ was added and the RNA was lysed by heat treatment $\left(70{ }^{\circ} \mathrm{C}, 10 \mathrm{~min}\right)$. A $10 \mu \mathrm{l}$ volume of $\mathrm{HCl}$ ( $1 \mathrm{M})$ was added to neutralize the solution; the cDNA samples were phenolized and precipitated with ethanol. The pellets were dissolved in a solution of $9.6 \mu \mathrm{l} \mathrm{Hi-Di}$ formamide (Applied Biosystems) and $0.4 \mu \mathrm{l}$ GeneScan LIZ-500 internal size standard (Applied Biosystems). Samples were heated to $95{ }^{\circ} \mathrm{C}$ for $5 \mathrm{~min}$, placed immediately on ice for $5 \mathrm{~min}$, and loaded onto an ABI PRISM 3130 sequencer (Applied Biosystems). To determine the product size accurately, sequencing reactions were performed with the same primer as the reverse transcription step and with the Thermo Sequenase Primer Cycle Sequencing kit (GE Healthcare). Reactions contained 400 ng plasmid DNA as template, and $2 \mathrm{pmol}$ of the corresponding primer. Cycling conditions were $95{ }^{\circ} \mathrm{C}$ for $30 \mathrm{~s}, 55{ }^{\circ} \mathrm{C}$ for $30 \mathrm{~s}$, and $72{ }^{\circ} \mathrm{C}$ for $60 \mathrm{~s}$, for a total of 60 cycles. The EDTA/ethanol-precipitated products of the four sequencing reactions were combined with the GeneScan LIZ-500 size standard and analysed on the DNA sequencer. Electrophoretograms were aligned according to the size standards using the GeneMapper 3.7 software (Applied Biosystems).

Bioinformatic analysis. The phylogenetic studies were done using the BLAST tree option on the NCBI Web BLAST service with the Fast Minimum Evolution method (Desper \& Gascuel, 2002) and the Kyoto Encyclopedia of Genes and Genomes (KEGG) database (Kanehisa et al., 2006). Comparative genomics was done using the Search Tool for the Retrieval of Interacting Genes/Proteins (STRING; von Mering et al., 2007). The percentages of sequence similarity between two proteins were calculated using the Needleman-Wunsch global alignment of the European Molecular Biology Open Software Suite (EMBOSS; Rice et al., 2000). The putative transmembrane segments (TMSs) were determined using the TopPred server (Claros \& von Heijne, 1994) and the TMpred server (Hofmann \& Stoffel, 1993). Prediction of signal peptides was done with the SignalP server (Bendtsen et al., 2004).

To identify and analyse putative binding sites of the response regulator PhoP, the information theory programs delila, makebk, encode, rseq, dalvec, ri, scan and lister (Schneider \& Stephens, 1990; Schneider, 1996, 1997) were used. Model 1 of Sola-Landa et al. (2008) provided the information content matrix to assign the information content $(R \mathrm{i})$ values.

\section{RESULTS}

\section{Two putative low-affinity phosphate transporters are encoded in the Streptomyces coelicolor genome}

Homology searches identified two putative low-affinity phosphate transport genes in the S. coelicolor genome, SCO4138 and SCO1845 (Bentley et al., 2002); they are designated in this work as pitH1 and pitH2, respectively, following the annotation of the homologous genes of Streptomyces avermitilis (Ikeda et al., 2003). The PitH1 and $\mathrm{PitH} 2$ proteins show 39 and $33 \%$ amino acid sequence similarity, respectively, to the transporter PitA of E. coli and contain the Pfam motif characteristic of the phosphate transporter family (PF01384 PHO4). Their sizes and similarities with homologous proteins are shown in Fig. 1. Both PitH1 and PitH2 contain putative TMSs.

In S. coelicolor, both pitH1 and pitH2 are clustered with genes encoding other proteins that may participate in phosphate transport. Firstly, pitH1 lies 8 bp downstream of a gene, SCO4137, that encodes a conserved protein containing a motif known as DUF47 (Pfam PF01865.7; Fig. 1). In Sinorhizobium meliloti, the homologous genes of SCO4137-pitH1 are considered to form an operon (orfApit). The orfA gene is annotated as pit-accessory, although the possible role of the OrfA protein in $\mathrm{P}_{\mathrm{i}}$ transport has not yet been investigated (Voegele et al., 1997; Bardin et al., 1998). In this work the SCO4137 protein is referred as Pitaccessory protein (Pap). On the other hand, downstream of pitH2 there is a gene (SCO1846) that encodes a membrane protein. The amino acid sequences of homologous proteins in other bacteria are poorly conserved, as expected for membrane proteins, but in all cases they contain two putative TMSs (Fig. 1). Comparative genomics showed that whereas the pap-pitH1 genetic organization is widespread in bacteria, the distribution of the pitH2-SCO1846 gene organization is confined to actinobacteria.

The upstream sequences of pitH2 and pap-pitH1 were selected for study of their transcriptional regulation by phosphate-limitation. Interestingly, bioinformatics analysis identified putative PhoP-binding sequences (PHO boxes) in the promoter region of $p i t H 2$, but no $\mathrm{PHO}$ boxes were found in the upstream region of pap-pitH1. The promoter of the $p s t S$ gene, which encodes the phosphate-binding transport protein, was also included in this study as a positive control PhoP-activated gene (Sola-Landa et al., 2005).

\section{Phosphate-limited and phosphate-replete cultures of wild-type and $\triangle p h o P$ mutant $S$. coelicolor strains}

In order to study phosphate regulation, $\mathrm{P}_{\mathrm{i}}$-limited and $\mathrm{P}_{\mathrm{i}^{-}}$ replete conditions were defined in initial experiments. Cultures of $S$. coelicolor wild-type and $\Delta p h o P$ mutant strains were carried out in $M G$ medium with initial $P_{i}$ concentrations of 2.1, 3.2 and $18.5 \mathrm{mM}$ (media designated MG-2.1, MG-3.2 and MG-18.5, respectively). The growth of both cultures was quite similar in MG-18.5 (Fig. 2a). Indeed, in MG-18.5, the $\mathrm{P}_{\mathrm{i}}$ concentration in the medium was in excess throughout the time-course of the culture (always higher than $4 \mathrm{mM}$ in both strains; Fig. 2a). For this reason, the MG-18.5 medium was chosen as the $\mathrm{P}_{\mathrm{i}}$-replete condition. On the other hand, an initial $\mathrm{P}_{\mathrm{i}}$ concentration of $2.1 \mathrm{mM}$ supported only poor growth of the $\Delta p h o P$ mutant, which can be explained by the lack of both PhoPdependent phosphate transport and a nutrient-limitation 


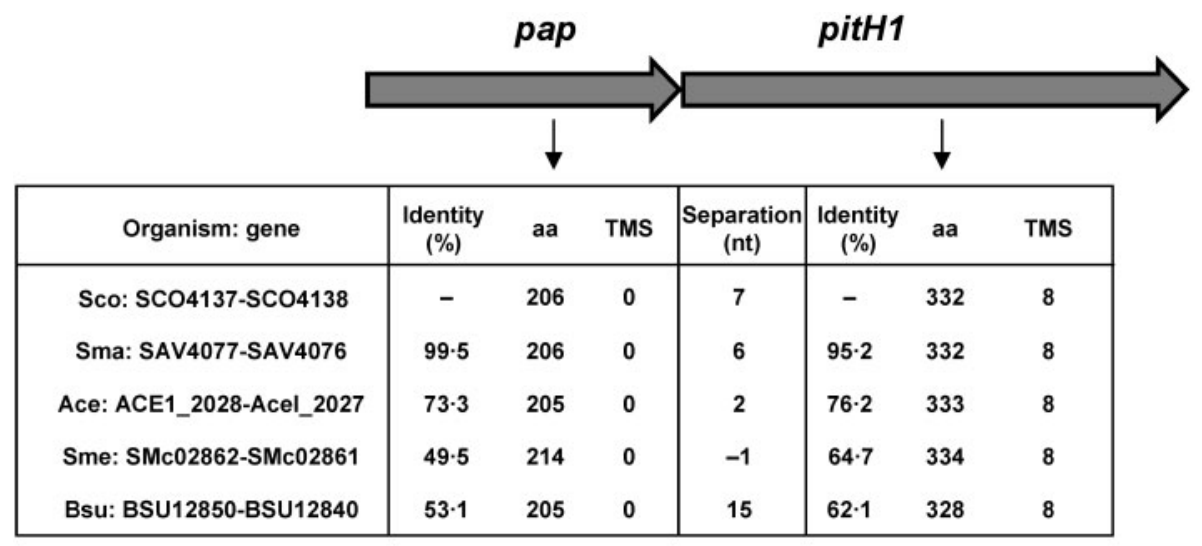

\begin{tabular}{|c|ccc|c|ccc|}
\hline \multicolumn{10}{c|}{ pitH2 } \\
\hline \multicolumn{10}{|c|}{+} \\
\hline Organism: gene & $\begin{array}{c}\text { Identity } \\
(\%)\end{array}$ & aa & TMS & $\begin{array}{c}\text { Separation } \\
\text { (nt) }\end{array}$ & $\begin{array}{c}\text { Identity } \\
\text { (\%) }\end{array}$ & aa & TMS \\
\hline Sco: SCO1845-SCO1846 & - & 423 & 10 & 34 & - & 73 & 2 \\
Sma: SAV6419-SAV6418 & 80.7 & 417 & 10 & 12 & 91.8 & 71 & 2 \\
Lxx: Lxx08880-Lxx08890 & 67.4 & 404 & 10 & -4 & 39.8 & 110 & 2 \\
Mtc: MT0570-MT0569 & 66.4 & 417 & 9 & -4 & 35.1 & 92 & 2 \\
Cgb: cg0545-cg0544 & 63.8 & 425 & 10 & -1 & 38.7 & 87 & 2 \\
\hline
\end{tabular}

Fig. 1. Map of the organization of pitH1 and pitH2 genes of $\mathrm{S}$. coelicolor. Below are tables summarizing the sequence similarity (including identical and functionally conserved amino acids) of the S. coelicolor (Sco) Pit proteins with Pit proteins of $S$. avermitilis (Sma), Acidothermus cellulolyticus (Ace), Sinorhizobium meliloti (Sme), B. subtilis (Bsu), Leifsonia xyli (Lxx), Mycobacterium tuberculosis (Mtc) and C. glutamicum ( $\mathrm{Cgb}$ ), the number of amino acids (aa) of the Pit proteins, the number of deduced TMSs and the separation (in nt) between the genes.

response; however, the growth of the wild-type strain was also severely reduced (results not shown). In contrast, MG3.2 medium allowed a substantial biomass increase in the $\Delta p h o P$ mutant during the first $44 \mathrm{~h}$, although the growth did not follow the diauxic pattern of the wild-type (Fig. 2b). About $85 \%$ of the initial $\mathrm{P}_{\mathrm{i}}$ was utilized in the first $40 \mathrm{~h}$ (corresponding with the rapid growth), and after $44 \mathrm{~h}$ it was mostly spent (coinciding with the end of the rapid growth phase), falling below $0.1 \mathrm{mM}$ in both wild-type and $\Delta$ phoP mutant cultures (Fig. 2b). The growth of the wildtype in MG-3.2 was also reduced as compared to the phosphate-replete condition (Fig. 2a, b). Therefore, MG3.2 was chosen as the $\mathrm{P}_{\mathrm{i}}$-limited condition.

\section{The pitH2 and pstS promoters, but not the pap-pitH1 one, are strongly induced under $\mathbf{P}_{\mathrm{i}}$-limited conditions}

To investigate how expression of pap-pitH1, pitH2 and pstS responds to $P_{i}$ concentration in the growth medium, their promoter regions were amplified, sequenced and cloned in the $\operatorname{pLUXAR}(+)$ promoter-probe plasmid, as described in Methods. Derivative plasmids were introduced by conjugation into both $S$. coelicolor wild-type and $\Delta p h o P$ mutant strains. The reporter activity was quantified in liquid cultures of phosphate-replete (MG-18.5) or phosphate-limited (MG-3.2) media (Fig. 3).

In the wild-type strain under conditions of phosphate limitation (MG-3.2), the activities of pstS, pitH2 and pappitH1 promoters followed a pattern of sequential induction that could be correlated with the decrease in $\mathrm{P}_{\mathrm{i}}$ concentration of the medium (compare Figs $2 b$ and $3 a$ ). As shown in Fig. 3(a), the maximum activity of pitH $2 p$ was reached at $40 \mathrm{~h}$, when the $\mathrm{P}_{\mathrm{i}}$ concentration had decreased to $0.5 \mathrm{mM}$; until $44 \mathrm{~h}$ of culture this was the major activity. This time $(44 \mathrm{~h})$ marked the end of the transition growth phase, as well as the maximum of pap-pitH1p activity, which showed a small delay with respect to the peak of $p i t H 2 p$ activity. Later, the $p s t S p$ activity became increasingly predominant. In fact, this is the only one of these promoter activities that can be 

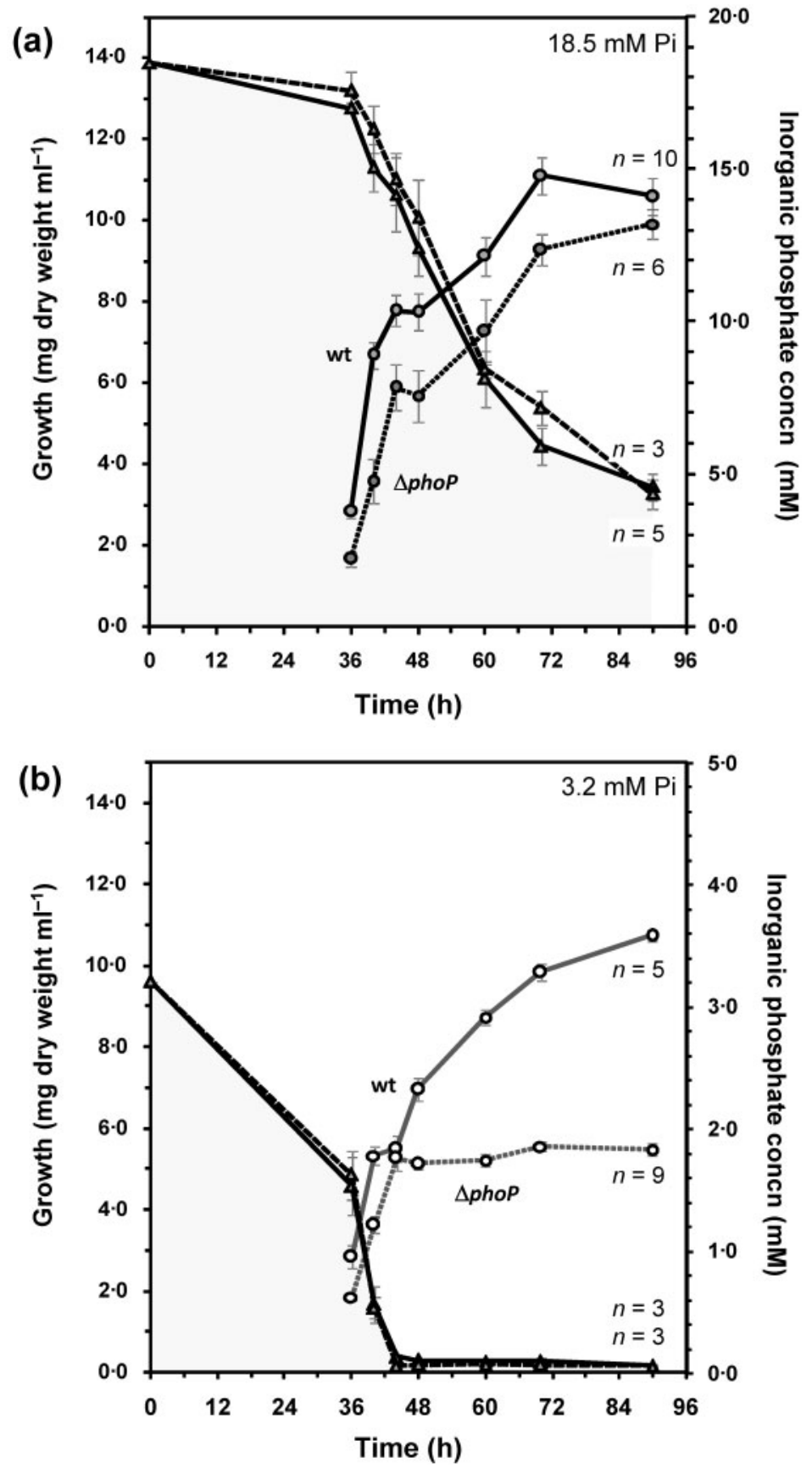

Fig. 2. Growth $(\bigcirc)$ and residual $P_{i}$ concentration $(\triangle)$ for $S$. coelicolor M145 (wild-type) and INB101 ( $\Delta$ phoP mutant) grown on MG18.5 (a) and MG-3.2 (b). In all cases the dashed line represents the $\Delta p h o P$ mutant strain. $n$, Number of independent experiments represented in each curve. Error bars, SEM. detected up to $70 \mathrm{~h}$. This is not surprising, since the Pst transporter is the high-affinity system that accounts for $\mathrm{P}_{\mathrm{i}}$ transport under conditions of low concentration (Rao \& Torriani, 1990). The highest induction of $p s t S p$ correlated with the drop of $\mathrm{P}_{\mathrm{i}}$ below $0.1 \mathrm{mM}$ (44-48 h; Figs $2 \mathrm{~b}$ and $3 \mathrm{a}$ ).

In MG-18.5, in which $P_{i}$ is in excess throughout the course of growth (Fig. 2a), the pattern of expression changed dramatically. Firstly, $p s t S$ promoter activity remained at very low levels throughout the culture (Fig. 3b). Secondly, the activity of $p i t H 2 p$ was constant until the late growth phase, and lacked the high levels reached in MG-3.2 at 40 and $44 \mathrm{~h}$ (compare Fig. 3a, b). The predominant activity in cultures in
MG-18.5 was that of pap-pitH1p throughout most of the culture. Indeed, its values increased 1.3-5.8-fold, as compared with that of the MG-3.2 culture, throughout the growth course. In conclusion, the pitH2 and pstS promoters are induced by $\mathrm{P}_{\mathrm{i}}$ limitation, while the pap-pitH1 promoter is more active under $\mathrm{P}_{\mathrm{i}}$-replete conditions.

\section{Expression of pitH2, but not that of pap-pitH1, is phoP-dependent}

The transcriptional regulator PhoP controls expression of the $p s S C A B$ transporter gene cluster by binding to the 

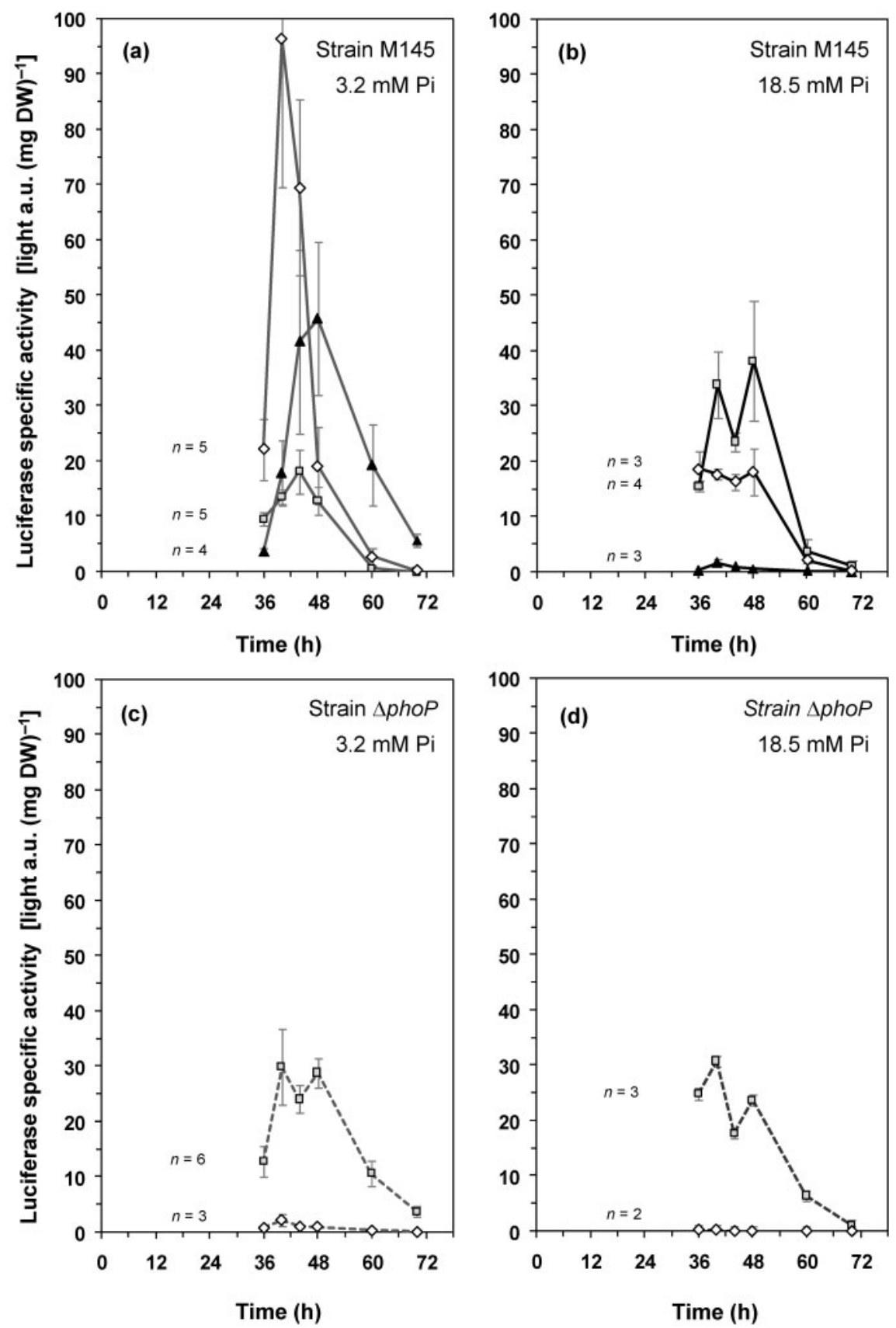

Fig. 3. Promoter activity of the exconjugants containing pLUX-pitH2 $(\diamond)$, pLUX-pitH1 ( $\square)$ and pLUX-pstS $(\mathbf{\Delta})$ derived from the wild-type M145 grown in MG-3.2 (a) and MG-18.5 (b), and from the $\Delta$ phoP mutant INB101 grown in MG-3.2 (c) and MG-18.5 (d). The same scale is used in the four panels for comparison. In all cases the dashed line represents the $\Delta p h o P$ mutant strain. $n$, Number of independent experiments represented in each curve. Error bars, SEM.

PHO box located in the pstS promoter (Sola-Landa et al., 2005). In order to study whether the expression of pappitH1 and pitH2 genes depends on the PhoP response regulator, reporter expression studies were performed with the $S$. coelicolor $\triangle p h o P$ mutant (Rodríguez-García et al., 2007). Results (Fig. 3c, d) clearly showed that expression of pitH2 was dependent upon the PhoP activator. In contrast, expression from the pap-pitH1 promoter was not affected by the lack of PhoP in the $\Delta p h o P$ mutant (Fig. 3c, d). Indeed, the pap-pitH1 activity was higher in the mutant than in the wild-type strain in MG-3.2 (1.7 times higher when the maximum values are compared). This result may reflect a mechanism of adaptation of pap-pitH1 to the lack of expression in the $\Delta$ phoP mutant of the other PhoP- 
dependent transporters, Pst and $\mathrm{PitH} 2$. In the $\Delta p h o P$ mutant grown in MG-18.5, the pap-pitH1 promoter showed a similar behaviour to that in the wild-type strain, although the values at 36 and $60 \mathrm{~h}$ were higher in the mutant than in the wild-type strain.

\section{Transcriptional analysis of pitH2 and pap-pitH1}

In order to confirm the promoter-probe results, RT-PCR was carried out as described in Methods using total RNA isolated from $40 \mathrm{~h} \mathrm{MG-3.2} \mathrm{cultures} \mathrm{of} \mathrm{both} \mathrm{wild-type} \mathrm{and}$ $\Delta p h o P$ mutant strains. Amplification of the pitH2 transcript was clearly detected in the wild-type RNA; in contrast, only a low-intensity band was present in the $\triangle p h o P$ mutant reaction, even after 40 cycles of PCR (Fig. 4a). The presence of a low level of $p i t H 2$ transcriptin in the $\triangle p h o P$ mutant correlates well with the very low, but significant, activity of the $p i t \mathrm{H} 2$ promoter at $40 \mathrm{~h}$ in the $\triangle$ phoP mutant (see Fig. 3c). On the other hand, both wildtype and mutant RNA gave rise to amplification products corresponding to pitH1 and pap-pitH1 transcripts (Fig. 4a). As expected, these results indicate that pap and pitH1 form a bicistronic transcript and are PhoP-independent.

The expression profile of $p i t H 2$ in the wild-type strain was studied in samples taken after 36, 40, 44 and $48 \mathrm{~h}$ of culture in MG-3.2 (Fig. 4b). Amplification of the cDNA from pitH2 transcripts is higher at the earlier times (36 and $40 \mathrm{~h}$ ) than the later ones ( 44 and $48 \mathrm{~h}$ ). Interestingly, maximum luciferase activities from the pit $2 p$-lux $A B$ fusion were observed $\sim 4 \mathrm{~h}$ later (Fig. 3a).

\section{PhoP binds to the pitH2 promoter but not to the pap-pitH1 promoter}

In order to test whether the PhoP protein binds to the pitH2 and pap-pitH1 promoters in vitro, the PhoP DNAbinding domain ( $\mathrm{PhoP}^{\mathrm{DBD}}$ ) fused to GST was used in binding assays, as described in Sola-Landa et al. (2005). The promoter DNA-PhoP interaction was studied by EMSA. A protein concentration of $0.25 \mu \mathrm{M}$ was sufficient to produce up to four complexes with the pitH2p DNA fragment (Fig. 5, arrows). As the protein concentration increased, the amount of unshifted probe decreased. However, no shifted bands were observed with the pappitH1 promoter under the same experimental conditions.

\section{Characterization of the pitH2 and pap-pitH1 promoters}

The transcription start site of the pitH2 promoter was determined by primer extension, using RNA from a $42 \mathrm{~h}$ culture in MG-3.2 of the S. coelicolor [pLUX-pitH2] exconjugant that corresponds to conditions of high promoter activity (Fig. 3a). Extension products with an apparent size of 76 and $166 \mathrm{nt}$, primed with LUXFAM +47 and LUX-FAM +135 , respectively, were observed clearly (Fig. 6). The same transcription start (a)
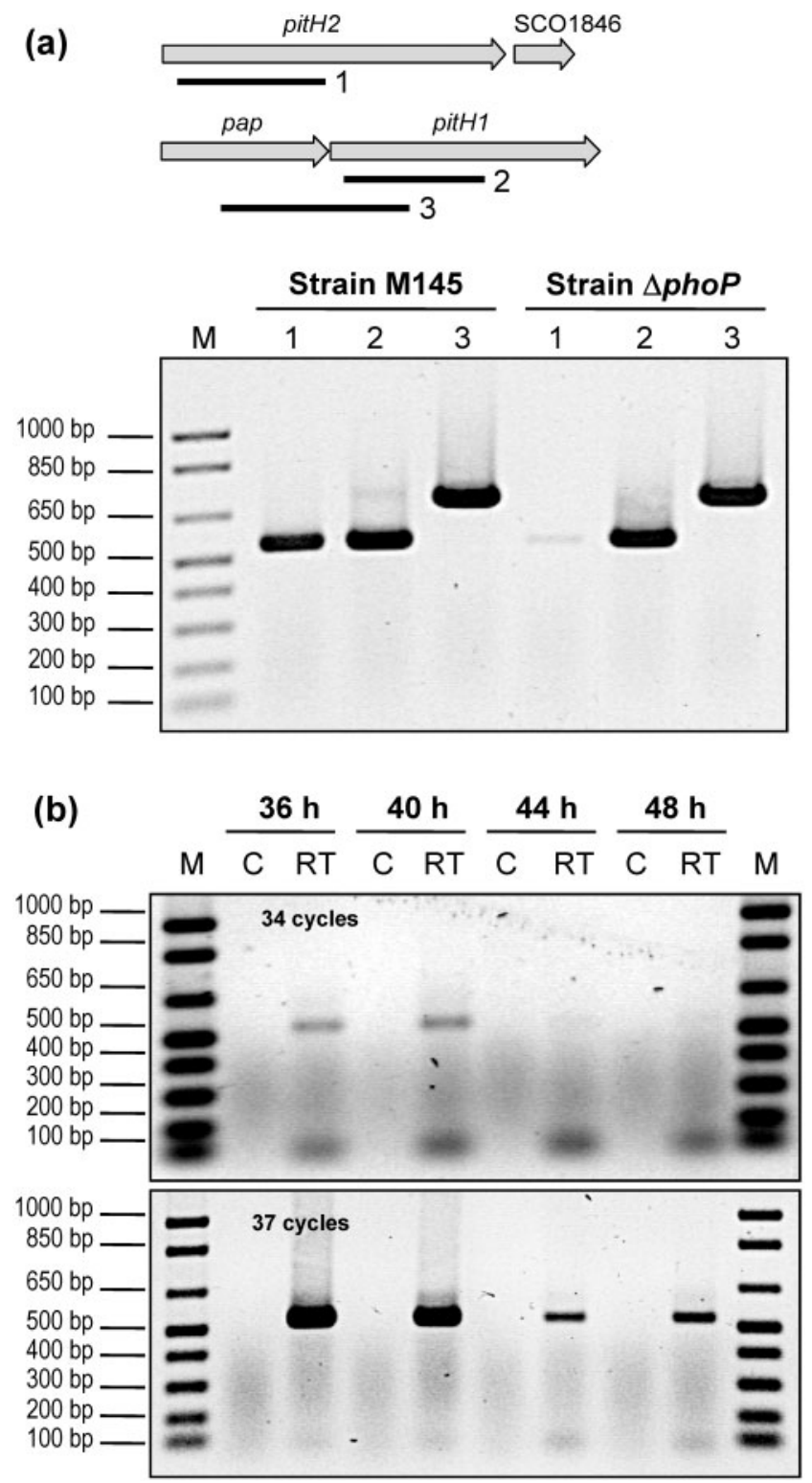

Fig. 4. RT-PCR analysis of the pitH2, pitH1 and pap-pitH1 transcripts in $S$. coelicolor M145 and $S$. coelicolor INB101 $(\triangle p h o P)$. The analysis was carried out as described in Methods. (a) The expected RT-PCR products 1, 2 and 3 of the pitH2 and pappitH1 genes are depicted above. Below, RT-PCR results (40 cycles) using total RNA from wild-type and $\triangle p h o P$ mutant cultures in MG-3.2 (40 h) as template. Lanes: M, 1 kb plus DNA ladder; 1 , amplification of a 542 bp fragment internal to pitH2; 2, amplification of a $541 \mathrm{bp}$ fragment internal to pitH1; 3, amplification of a 697 bp fragment covering both pap and pitH1 coding sequences. The absence of contaminating DNA in the RNA samples was assessed using Platinum Taq (data not shown). (b) RT-PCR amplification of the pitH2 transcript. Template total RNAs were isolated at 36, 40, 44 and $48 \mathrm{~h}$ from a wild-type MG-3.2 culture. Lanes: C, control reactions with Platinum Taq; RT, reverse trancriptase reactions. Upper panel, 34 cycles of amplification; lower panel, 37 cycles. 


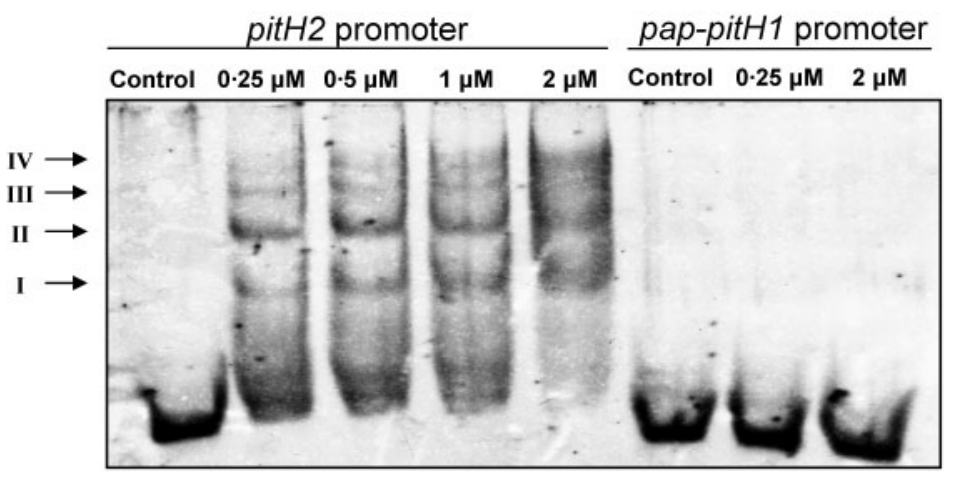

Fig. 5. EMSAs of the pitH2 and pap-pitH1 promoters. Control, probe without protein. Other lanes, increasing concentrations (0.25, $0.5,1$ and $2 \mu \mathrm{M})$ of the GST-PhoP ${ }^{\mathrm{DBD}}$ protein (DNA-binding domain). For pap-pitH1, only 0.25 and $2 \mu \mathrm{M}$ protein concentrations were used. Note the lack of binding to the pap-pitH1 promoter.

point (TSP) was deduced from both products when compared with the respective sequencing reactions. This corresponds to a guanine located $32 \mathrm{bp}$ upstream of the ATG codon (Fig. 6). Sequences resembling the -10 and -35 consensus (Strohl, 1992) were located at the proper distance from the TSP, centred at positions -7 and -33 , respectively. These -10 and -35 boxes overlap the PhoPbinding site (Fig. 8). Although the distance between the
-10 and -35 boxes (20 nt) is longer than usual (16$18 \mathrm{nt}$ ), this feature seems to be a characteristic of the PhoPdependent activation mechanism of this and other genes (see Discussion).

Following the research of Strohl (1992), the pap-pitH1 upstream sequences TTAGCA-N18-TAGCAT constitute plausible -35 and -10 promoter boxes (located at (a)

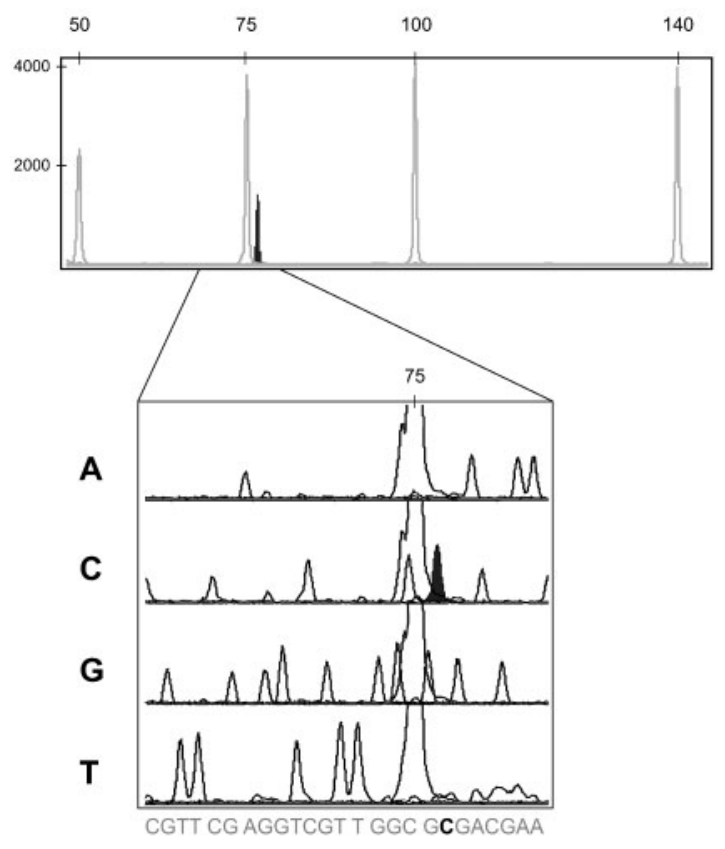

(b)

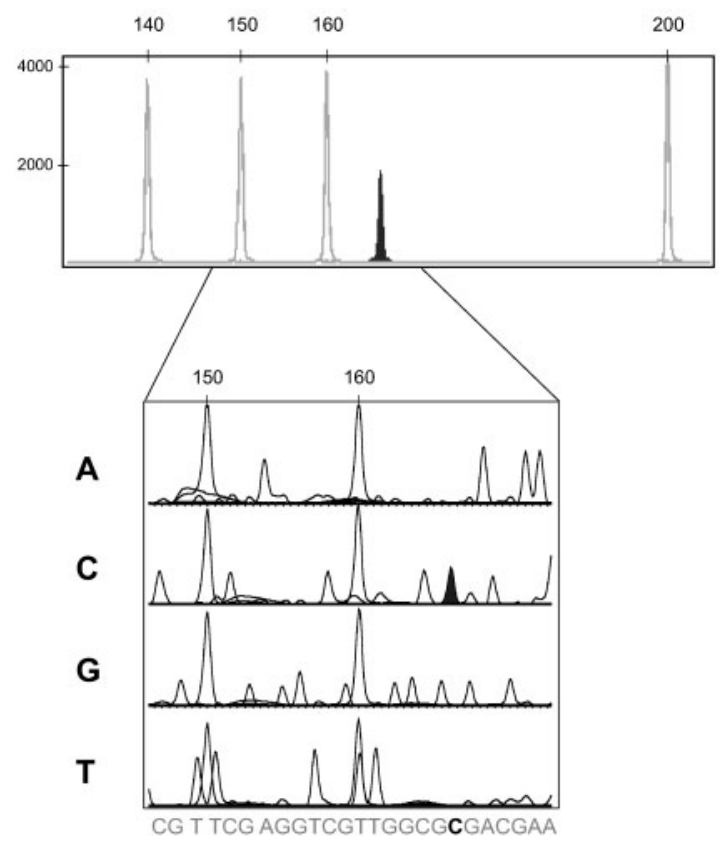

Fig. 6. Primer extension analysis of the pitH2 promoter using automated fluorescent capillary electrophoresis. Primer extension reactions were done with both the LUX-FAM + 47 (a) and LUX-FAM + 135 (b) primers. In the upper fluorograms, the black-filled peaks represent the extension products (FAM-labelled cDNA) and the grey traces represent the LIZ-500 standards that were included in each sample. Standard sizes are marked on the upper axis, and fluorescence intensities are indicated as arbitrary units on the $y$ axis. The expanded lower fluorograms correspond to the four sequencing reactions $(A, C, G$ and $T)$ obtained with the Thermo Sequenase kit using the respective primers. Size standards were also included and the apparent molecular sizes were determined using GeneMapper software. Each black-filled peak corresponds to the sequencing product with the same apparent size as the respective extension fragment. In both primer extension reactions the same base (the $\mathrm{C}$ shown in bold type; note that this is the non-coding strand) was established as the transcription start site of the pitH2 gene. 
positions -61 and -37 , respectively, from the translation start codon). However, we have failed to obtain clear extension products with the pap-pitH1 promoter, despite exhaustive trials. Retrotranscription reactions were done with five different RNA samples from wild-type and mutant cultures using two different enzymes (Superscript II and Superscript III, both from Invitrogen), two different primers (LUX-FAM +47 and LUX-FAM +135 ), varying the amounts of RNA (5-200 $\mu \mathrm{g})$ and primer $(5-50 \mathrm{pmol})$, varying reaction time and temperature $\left(5-15 \mathrm{~h} ; 42-50{ }^{\circ} \mathrm{C}\right)$, and with or without DMSO (5\%) or actinomycin D. The lack of detected extension products also occurs in the Sinorhizobium meliloti wild-type strain carrying only one copy of the orfA-pit gene region (Bardin et al., 1998), and suggests that the pap-pitH1 transcript may be rapidly degraded, thus precluding retrotranscription.

\section{Analysis of the PhoP-binding sequence in the pitH2 promoter}

To determine the PhoP-binding sequence, DNase I footprinting of the pitH2 promoter region in the presence and absence of $\mathrm{PhoP}^{\mathrm{DBD}}$ was performed as described previously (Rodríguez-García et al., 1997; Sola-Landa et al., 2005). $\mathrm{Pho} \mathrm{P}^{\mathrm{DBD}}$ was found to protect a $69 \mathrm{bp}$ region in the pitH2 promoter. The protected sequence was of $53 \mathrm{nt}$ in the pitH2 coding strand and $64 \mathrm{nt}$ in the complementary strand; $48 \mathrm{nt}$ were coincident in both strands (Figs 7 and 8 ). Full protection of the coding strand was achieved at $0.5 \mu \mathrm{M}$ GST-PhoP ${ }^{\mathrm{DBD}}$, and the protected region was not enlarged by increasing protein concentration (Fig. 7a). The protection of the complementary strand showed the same requirement for GST-PhoP ${ }^{\text {DBD }}$ protein $(0.5 \mu \mathrm{M})$, and the protected sequence was not enlarged by increasing protein concentration (Fig. 7b). However, when a protein concentration of $0.26 \mu \mathrm{M}$ was used, the protected region was shortened in the upstream and downstream regions (see the marked traces of the fluorograms in Fig. 7b), suggesting that the core region of the protected region has a higher affinity for PhoP than the adjacent nucleotide sequences (see below).

The information theory (Schneider, 1996, 1997) analysis of this pitH2 region revealed six DRus of $11 \mathrm{nt}$ in length using the published matrix model I (Sola-Landa et al., 2008). The central sequence of the $\mathrm{pitH} 2$ protected region contains four consecutive DRus (DRu-1, DRu-2, DRu-3 and DRu4 ), and the flanking sequences contained two additional repeats, DRu-A and DRu-B. Both DRu-A and DRu-B are separated from the central repeats by 1 and $2 \mathrm{bp}$, respectively (Figs 7 and 8 ). The individual $R \mathrm{i}$ values indicate that three of the DRus in the pitH2 operator (DRu-1, DRu-3 and DRu-4) are well conserved, whereas $\mathrm{DRu}-2$ is poorly conserved (Fig. 8). The $\mathrm{DRu}-\mathrm{A}$ and $\mathrm{DRu}-$ $\mathrm{B}$ sequences, in contrast, show a negative $R \mathrm{i}$ that reflects a poor sequence conservation (Fig. 8). The binding of PhoP to these poorly conserved DRus can be explained by a cooperative interaction between consecutive protein monomers at high protein concentration. We have proposed elsewhere (Sola-Landa et al., 2008), for these complex operator structures, that at lower PhoP concentrations only DRu-3 and DRu-4 are bound, and these form the core of the site. Higher PhoP concentrations would allow the sequential binding to $\mathrm{DRu}-1-\mathrm{DRu}-2, \mathrm{DRu}-\mathrm{A}$ and DRu-B (Fig. 8; see Discussion). This explains the appearance of up to four retarded complexes in the EMSA assays (Fig. 5).

\section{DISCUSSION}

Phosphate deprivation in bacteria triggers the $\mathrm{PHO}$ regulon, which includes a series of extracellular enzymes involved in phosphate scavenging from organic phosphates. In S. coelicolor these include at least a phytase gene, two glycerophosphodiester phosphodiesterase genes (Rodríguez-García et al., 2007) and four phosphatase genes (Apel et al., 2007; Sola-Landa et al., 2008). As a parallel strategy to survive $\mathrm{P}_{\mathrm{i}}$ starvation, Streptomyces cells may consume phosphorous storage material, such as polyphosphates, nucleotides and teichoic acids. The $p p k$ gene, which encodes an enzyme that catalyses the reversible polymerization of the $\gamma$ phosphate of ATP into polyphosphate, is under the positive control of the PhoR-PhoP system in Streptomyces lividans (Ghorbel et al., 2006). Moreover, two PhoP-binding sites have been found in a cluster of genes putatively involved in the biosynthesis of cell wall polysaccharides, so that phosphate-free polymers could substitute for phosphate-rich polymers in the cell wall (Rodríguez-García et al., 2007).

Inorganic phosphate transport (Pit) proteins are found in all groups of living organisms, including bacteria, archaea, yeast, fungi, plants and animals. pit genes encoding proteins from 195 to 763 aa in length are found in different organisms (Saier et al., 1999). In some bacteria the Pit system has been proposed to have a role in heavy metal tolerance; thus, in the presence of heavy metals, metal phosphates are transported out of the cell by Pit (Keasling, 1997; Beard et al., 2000; Álvarez \& Jerez, 2004).

Three $\mathrm{P}_{\mathrm{i}}$ transport systems have been identified in the genome of S. coelicolor. Of these three, PitH1 is the major transporter when $\mathrm{P}_{\mathrm{i}}$ is in excess, whereas $\mathrm{PitH} 2$ and Pst work when $\mathrm{P}_{\mathrm{i}}$ is limited. In E. coli there are two pit genes as well, although PitA and PitB share greater sequence similarity $(90 \%)$ than PitH1 and PitH2 in S. coelicolor (53\%), and have the same topological structures (10 TMS; Harris et al., 2001). Moreover, the S. coelicolor pit genes are clustered with distinct accessory genes (Fig. 1), which is not the case for E. coli. On the other hand, in Acinetobacter johnsonii, Sinorhizobium meliloti and other bacteria, there is only one pit gene.

The pit genes can also be classified according to their regulation. We have described the regulation of the pappitH1 and pitH2 genes above. The pitH2 gene is PhoPdependent, while the pap-pitH1 one is not. In E. coli the 


\section{(a) Coding strand}

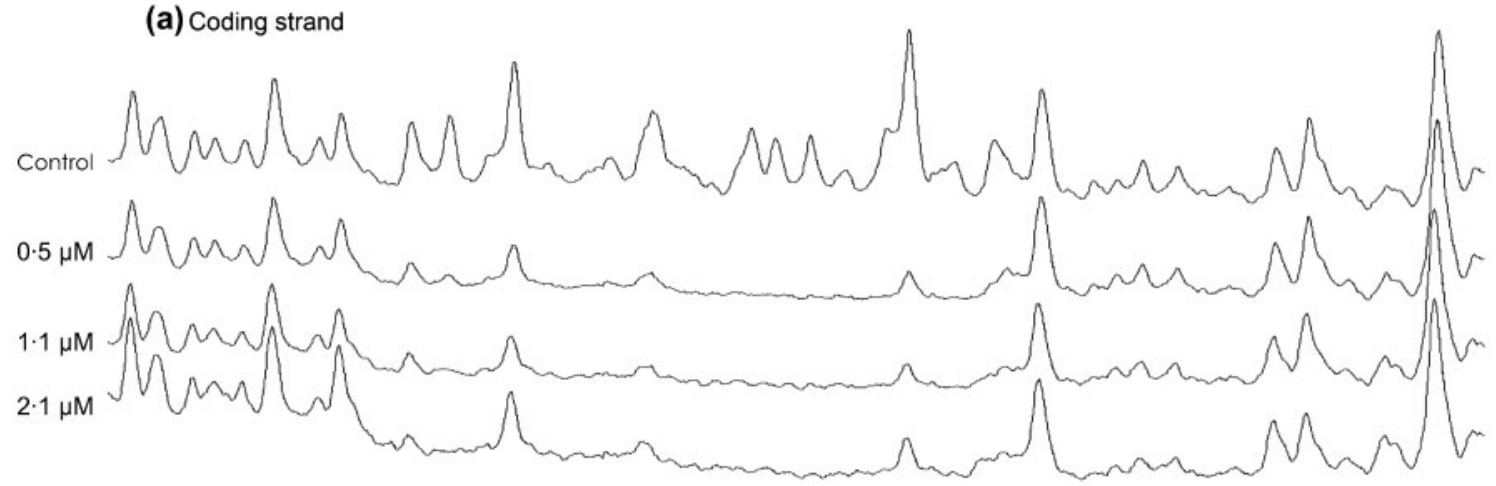

CGGAGCGGGCACGCAGAGGGAGGCCGCGACCCCGCTTCCGGTCACCGTGGCGCCCTGCCCAGTTCATCTTCCG TT C ACCCTGGTIACTT ACGTTCGTCGCGCC AACG ACCT

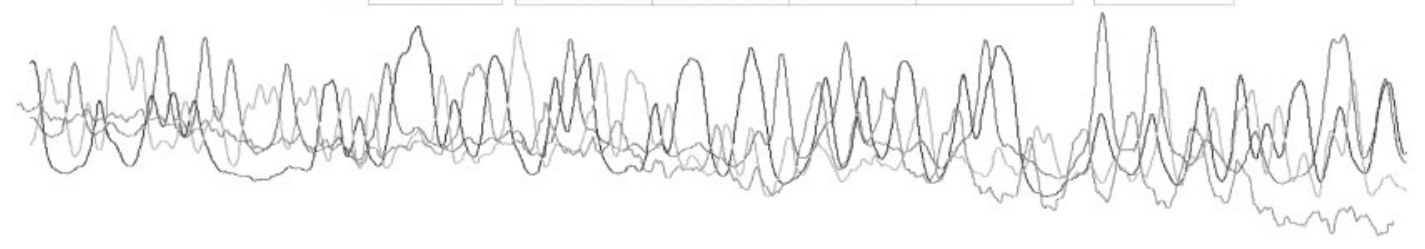

(b) Complementary strand

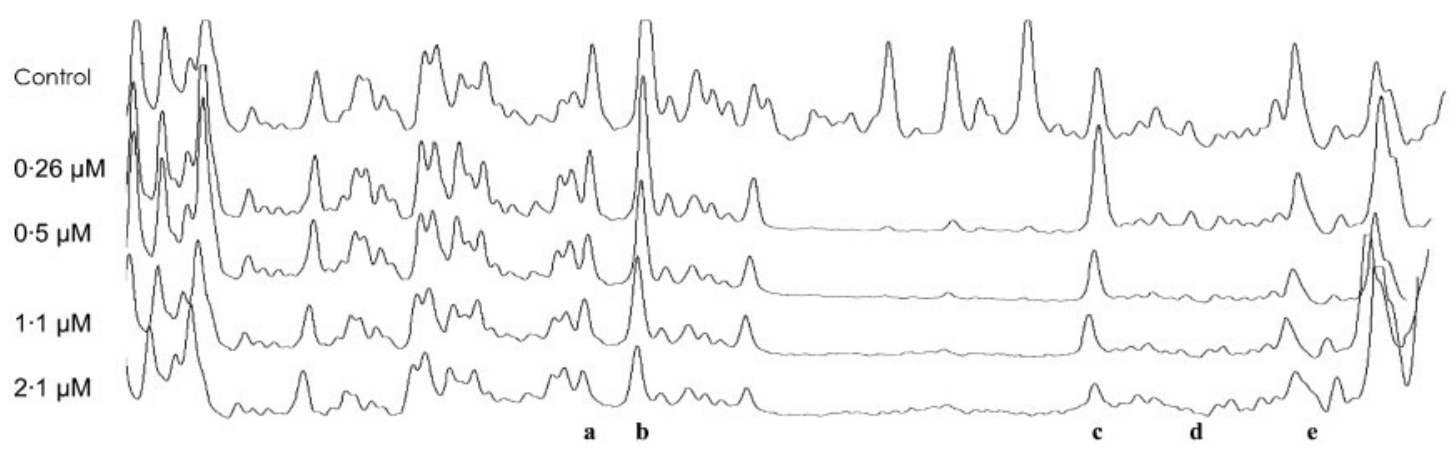

TACCCAGGCAATCGTTCGAGGTCGTTGGCGCG AC G AA CGTAAGTAACCAGGGTGAACGGAAGATGAACTGGGCAGGGCGCCACGGTGACCGGAAGCGGGGTOGCGGC

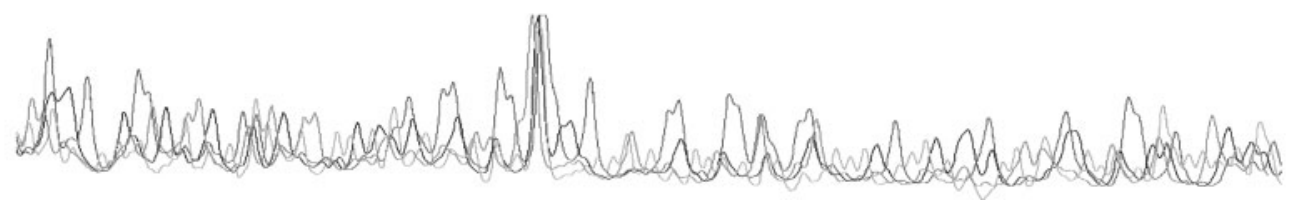

Fig. 7. Footprinting of the coding (a) and the complementary (b) strands of the pitH2 promoter region using GST-PhoPDBD. The upper fluorograms correspond to the control DNA (without protein) and to the protected reaction (with increasing concentrations of protein). The lower fluorograms correspond to the full nucleotide sequence used as the molecular mass marker. The protected nucleotide sequence is indicated in bold type, and the direct repeats that form the PHO operator are boxed. The letters a-e represent the main peaks that decrease as the protein concentration increases in the complementary strand. Note that the protection is hardly detected between peaks a and b, and not detected between peaks $c$ and e when the lowest protein concentration $(0.26 \mu \mathrm{M})$ is used.

pitA promoter is constitutive, but the pitB promoter appears to be repressed by $\mathrm{PhoB}$ (the PhoP orthologue) (Elvin et al., 1986; Harris et al., 2001). Both patterns of regulation were also found in different organisms with a single pit gene. In $A$. johnsonii, the pit gene is expressed constitutively (van Veen et al., 1993; van Veen, 1997), whereas in Sinorhizobium meliloti it is repressed by PhoB (Bardin \& Finan, 1998; Bardin et al., 1998; Yuan et al., 


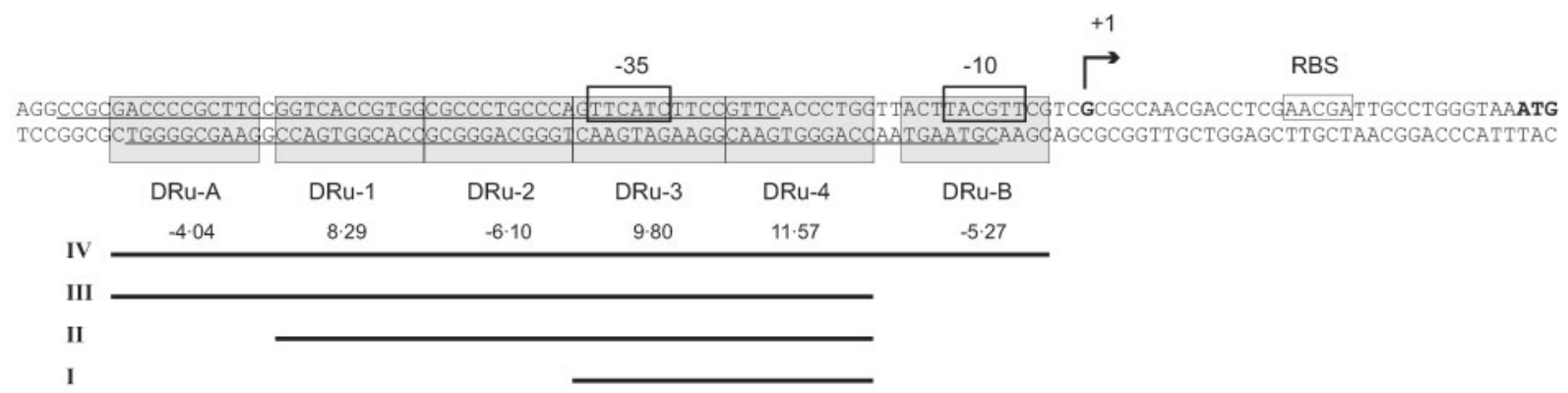

Fig. 8. Promoter region of pitH2. DRus are indicated by shaded boxes. The number below each $\mathrm{DRu}$ is the $R \mathrm{i}$ value. The region protected by $\mathrm{PhoP} \mathrm{PBD}^{\mathrm{DB}}$ in DNase footprinting assays is underlined in the corresponding strand. The -10 and -35 hexanucleotides are boxed. The TSP is indicated by a bent arrow and bold type. Nucleotides showing homology with the $16 \mathrm{~S}$ RNA, which could form a ribosome-binding site, are framed with a box labelled RBS. The start codon is shown in bold type. The bars with roman numerals represent the expected DRus that participate in each shifted band of the EMSA experiment.

2006a, b). In Corynebacterium glutamicum the pit gene has also been proposed to be repressed by PhoR, the response regulator of the two-component PhoS-PhoR (Schaaf \& Bott, 2007). Similarly, the Myxococcus xanthus pit gene is repressed in phosphate-starved cells. This repression is not observed in a mutant in phoP4, which is one of the four response regulators involved in the $\mathrm{PHO}$ response in this organism (Whitworth et al., 2008). In contrast, PhoP positively regulates pitH2 of $S$. coelicolor. To our knowledge, this is the first pit gene to be described as PhoPupregulated in bacteria, suggesting that the mechanism of action of the phosphate response regulator may be positive in some bacteria and negative in others.

As shown in this work, in the $\Delta p h o P$ mutant only the pappitH1 promoter is active, but both wild-type and mutant strains take up $\mathrm{P}_{\mathrm{i}}$ from the medium with similar efficiency (Fig. 2). Gebhard et al. (2006) proposed that the loss of one or two $\mathrm{P}_{\mathrm{i}}$ transport systems can be compensated for by increased activity of the remaining systems. It is reasonable to assume that the higher pitH1 expression in the $S$. coelicolor $\triangle p h o P$ mutant serves to compensate for the lack of the other two transport systems (Fig. 3). Additionally, another pst operon could exist in S. coelicolor (SCO6816SCO6814), as suggested by Díaz et al. (2005). Two specific $\mathrm{ABC} \mathrm{P}_{\mathrm{i}}$ transport systems have been described in various bacteria, such as Sinorhizobium meliloti (Voegele et al., 1997; Yuan et al., 2006a) and some species of mycobacteria (Braibant et al., 1996; Gebhard et al., 2006).

The $\Delta p h o P$ mutant did not grow after $44 \mathrm{~h}$ in phosphatelimited MG-3.2 medium, when the $P_{i}$ concentration dropped below $0.1 \mathrm{mM}$ (Fig. 2b). This is probably due to the fact that the $\triangle p h o P$ mutant is defective in the expression of PhoP-dependent genes. The mutant strain has an altered expression of genes involved in central metabolism and protein synthesis, which are PhoP upregulated (Rodríguez-García et al., 2007).

Although transcription from pitH2 and pstS promoters is PhoP-dependent, the two genes showed different patterns of expression. Firstly, sequential activation and decay of the reporter activity at distinct levels of residual $\mathrm{P}_{\mathrm{i}}$ are evident from the results. The first gene induced in MG-3.2 medium was pitH2, encoding the low-affinity transporter (Fig. 3a). It makes sense that when the $P_{i}$ in the medium falls, the bacterium first responds with high induction of a lowaffinity transporter (pit), since this system is energetically less expensive to the cell than the pst system. The expression of pst occurs when the $\mathrm{P}_{\mathrm{i}}$ in the medium becomes scarce, which is consistent with the higher affinity of this transporter.

In phosphate-replete cultures the pitH2 promoter was constantly active from 36 to $48 \mathrm{~h}$, while pstS promoter activity was nearly absent (Fig. 3b). We propose two mechanisms to explain the differences between pitH2 and pstS expression: (i) the different structure of the PhoPbinding sites, and (ii) the interaction of $\mathrm{PhoP}$ with specific sigma factors. These mechanisms, which can act together, are based on the operator structures and might involve the participation of alternative sigma factors.

The differences in structure of the PhoP-binding sites in the promoters of pitH2 and pstS provide mechanisms to explain their expression patterns. The $\mathrm{PHO}$ box of pstS is composed of two well-conserved DRus located upstream of the promoter elements (Sola-Landa et al., 2005). In contrast, EMSA, footprinting and information content analysis of the pitH2 operator revealed a complex structure of six DRus. It is proposed, following the model of SolaLanda et al. (2008), that phosphorylated PhoP (PhoP P) binds first to the most conserved DRu-3 and DRu-4 sequences, which form the core of the binding site. Increasing concentrations of $\mathrm{PhoP} \sim \mathrm{P}$ would result in the consecutive occupancy of DRu-1 and DRu-2. Since the last $\mathrm{DRu}$ shows a negative $\mathrm{Ri}$ (Fig. 8), the binding here of a protein monomer can be explained by protein-protein interactions, as proposed previously for the phoRP operator (Sola-Landa et al., 2005). Higher concentrations of $\mathrm{PhoP} \sim \mathrm{P}$ would allow the binding of $\mathrm{DRu}-\mathrm{A}$ and $\mathrm{DRu}-\mathrm{B}$, 
although the relevance to the control of gene expression of the binding of PhoP to this sequence may be minor. The functionality of a DRu separated by 2 bp has already been demonstrated for the phoD promoter (Apel et al., 2007) and the SCO1196 operator (Sola-Landa et al., 2008). This stoichiometry matches the number of EMSA complexes observed (Figs 5 and 8).

The position of these DRus in relation to the promoter elements accounts for the dual role, positive and negative, of PhoP, as occurs in the phyC gene of Bacillus amyloliquefaciens (Makarewicz et al., 2006). The main features of the phyC promoter are: (i) one PHO box overlapping the -35 element; (ii) an improper spacing with the -10 element $(21 \mathrm{bp})$; and (iii) a direct repeat overlapping the -10 element. Makarewicz et al. (2006) have proved that while binding of PhoP at -35 is essential for activation of the promoter, binding of $\mathrm{PhoP}$ at -10 suppresses promoter activity. Similarly, the PhoP operator core in the pitH2 promoter overlaps the -35 region (Fig. 8); the separation from the -10 element is $20 \mathrm{bp}$, which is larger than those of standard Streptomyces promoters (16-18 bp; Strohl, 1992), and DRu-B overlaps the -10 region of the pitH2 promoter (Fig. 8 ). This is a characteristic feature of some promoters regulated by dual activator/repressor proteins (Hidalgo \& Demple, 1997; Makarewicz et al., 2006). With this model in mind, PhoP P oligomerization on the DNA up to DRus A, 1, 2, 3 and 4 would result in the activation of the pitH2 promoter. However, the binding of $\mathrm{PhoP} \sim \mathrm{P}$ to $\mathrm{DRu}-\mathrm{B}$ would cause repression. The repression at the highest $\mathrm{PhoP} \sim \mathrm{P}$ concentrations is in agreement with the rapid activity drop of the pitH2 promoter from 40 to $48 \mathrm{~h}$, coincident with the rise in $p s t S p$ activity (Fig. 3a).

The homologous pitH2 gene in S. avermitilis (SAV6419) also has a PhoP-binding site in its promoter region with a similar structure, which supports our proposed model. In this species, there are two highly conserved DRus with $R$ i values of 9.8 and 11.6 bits, respectively. As in S. coelicolor, downstream of these DRus, separated by $2 \mathrm{bp}$, there is another DRu with an $\mathrm{Ri}$ of 0.1 bits. This $\mathrm{DRu}$ should be the functional homologue of S. coelicolor DRu-B in the pitH2 promoter.

The earlier activation of the pitH2 gene with respect to the $p s t S$ gene can be also explained if its promoter is recognized by a sigma factor, active in the first phase of growth, that interacts with $\mathrm{PhoP}$, whereas $p s t S$ is triggered by $\mathrm{PhoP}$ in combination with a phosphate-limitation-responsive sigma factor. This mechanism is supported by the finding that the Bacillus subtilis PhoP is able to interact with promoters of at least three different sigma factors $\sigma^{\mathrm{A}}, \sigma^{\mathrm{E}}$ and $\sigma^{\mathrm{M}}$ (Paul $e t$ al., 2004; Minnig et al., 2005). The sequencing of the $S$. coelicolor genome has identified a plethora of genes that encode sigma-factors, including four homologues ( $\mathrm{rd} d A$, $h r d B, h r d C$ and $h r d D$ ) of the principal sigma factors, nine homologues of $B$. subtilis stress-response $\sigma^{\mathrm{B}}$, and 51 extracytoplasmic function sigma factors (Bentley et al., 2002; Hahn et al., 2003). Therefore, it will not be surprising if one or more sigma factors are dedicated to the phosphate-limitation stress response. Moreover, the sigma factor genes $h r d B$ and $h r d D$ of Streptomyces griseus are expressed differentially under $\mathrm{P}_{\mathrm{i}}$-rich or $\mathrm{P}_{\mathrm{i}}$-starved conditions, respectively (Marcos et al., 1995).

Finally, the pitH2 promoter activity in phosphate-replete cultures (Fig. 3b) indicates that unphosphorylated PhoP can bind and activate this promoter. In vitro DNA binding of the unphosphorylated PhoP (the PhoP form existing under high-phosphate conditions) proteins of $S$. coelicolor (Sola-Landa et al., 2005) and B. subtilis has been reported, although in B. subtilis, the phosphorylated protein is required for full activation (Liu et al., 1998; Eder et al., 1999). Also, in S. coelicolor, the full pitH2 promoter activity is achieved under conditions of phosphate limitation, i.e. when PhoP is phosphorylated.

\section{ACKNOWLEDGEMENTS}

This work was supported by grants from the 'Comisión Interministerial de Ciencia y Tecnología' (BIO2003-01489, BIO2006-14853-C02-01); the 'Ministerio de Educación, Ciencia y Tecnología', Madrid (GEN2003-20245-C09-01); the ERA-NET SySMO Project (GEN2006-27745-E/SYS) and the European Union (ACTINOGEN LSHM-CT-2004-005224). F. S.-B. received a fellowship of the FPI program (Ministerio de Educación, Spain), and E. F.-D. was supported by a fellowship of the Diputación de León. We acknowledge the excellent technical help of B. Martín, J. Merino, A. Casenave and B. Aguado.

\section{REFERENCES}

Altermann, E., Klein, J. R. \& Henrich, B. (1999). Synthesis and automated detection of fluorescently labeled primer extension products. Biotechniques 26, 96-101.

Álvarez, S. \& Jerez, C. A. (2004). Copper ions stimulate polyphosphate degradation and phosphate efflux in Acidithiobacillus ferrooxidans. Appl Environ Microbiol 70, 5177-5182.

Apel, A. K., Sola-Landa, A., Rodriguez-Garcia, A. \& Martín, J. F. (2007). Phosphate control of phoA, phoC and phoD gene expression in Streptomyces coelicolor reveals significant differences in binding of PhoP to their promoter regions. Microbiology 153, 3527-3537.

Bardin, S. D. \& Finan, T. M. (1998). Regulation of phosphate assimilation in Rhizobium (Sinorhizobium) meliloti. Genetics 148, 1689-1700.

Bardin, S. D., Voegele, R. T. \& Finan, T. M. (1998). Phosphate assimilation in Rhizobium (Sinorhizobium) meliloti: identification of a pit-like gene. J Bacteriol 180, 4219-4226.

Beard, S. J., Hashim, R., Wu, G., Binet, M. R., Hughes, M. N. \& Poole, R. K. (2000). Evidence for the transport of zinc(II) ions via the Pit inorganic phosphate transport system in Escherichia coli. FEMS Microbiol Lett 184, 231-235.

Bendtsen, J. D., Nielsen, H., von Heijne, G. \& Brunak, S. (2004). Improved prediction of signal peptides: SignalP 3.0. J Mol Biol 340, 783-795.

Bentley, S. D., Chater, K. F., Cerdeno-Tarraga, A. M., Challis, G. L., Thomson, N. R., James, K. D., Harris, D. E., Quail, M. A., Kieser, H. \& other authors (2002). Complete genome sequence of the model actinomycete Streptomyces coelicolor A3(2). Nature 417, 141-147. 
Bérdy, J. (2005). Bioactive microbial metabolites. J Antibiot (Tokyo) 58, $1-26$.

Braibant, M., Lefevre, P., de Wit, L., Ooms, J., Peirs, P., Huygen, K., Wattiez, R. \& Content, J. (1996). Identification of a second Mycobacterium tuberculosis gene cluster encoding proteins of an ABC phosphate transporter. FEBS Lett 394, 206-212.

Chater, K. F. \& Bibb, M. J. (1997). Regulation of Bacterial Antibiotic Production. In Biotechnology, vol. 7: Products of Secondary Metabolism, pp 57-105. Edited by H. Kleinkauf \& H. von Döhren. Weinheim, Germany: VCH.

Claros, M. G. \& von Heijne, G. (1994). TopPred II: an improved software for membrane protein structure predictions. Comput Appl Biosci 10, 685-686.

Desper, R. \& Gascuel, O. (2002). Fast and accurate phylogeny reconstruction algorithms based on the minimum-evolution principle. J Comput Biol 9, 687-705.

Díaz, M., Esteban, A., Fernandez-Abalos, J. M. \& Santamaria, R. I. (2005). The high-affinity phosphate-binding protein PstS is accumulated under high fructose concentrations and mutation of the corresponding gene affects differentiation in Streptomyces lividans. Microbiology 151, 2583-2592.

Doull, J. L. \& Vining, L. C. (1989). Culture conditions promoting dispersed growth and biphasic production of actinorhodin in shaken cultures of Streptomyces coelicolor A3(2). FEMS Microbiol Lett 53, 265-268.

Eder, S., Liu, W. \& Hulett, F. M. (1999). Mutational analysis of the phoD promoter in Bacillus subtilis: implications for PhoP binding and promoter activation of Pho regulon promoters. J Bacteriol 181, 20172025 .

Elvin, C. M., Dixon, N. E. \& Rosenberg, H. (1986). Molecular cloning of the phosphate (inorganic) transport (pit) gene of Escherichia coli K12. Identification of the pit + gene product and physical mapping of the pit-gor region of the chromosome. Mol Gen Genet 204, 477-484.

Fekete, R. A., Miller, M. J. \& Chattoraj, D. K. (2003). Fluorescently labeled oligonucleotide extension, a rapid and quantitative protocol for primer extension. Biotechniques 35, 90-98.

Gebhard, S., Tran, S. L. \& Cook, G. M. (2006). The Phn system of Mycobacterium smegmatis: a second high-affinity ABC-transporter for phosphate. Microbiology 152, 3453-3465.

Ghorbel, S., Smirnov, A., Chouayekh, H., Sperandio, B., Esnault, C., Kormanec, J. \& Virolle, M. J. (2006). Regulation of $p p k$ expression and in vivo function of Ppk in Streptomyces lividans TK24. J Bacteriol 188, 6269-6276.

Hahn, M. Y., Bae, J. B., Park, J. H. \& Roe, J. H. (2003). Isolation and characterization of Streptomyces coelicolor RNA polymerase, its sigma, and antisigma factors. Methods Enzymol 370, 73-82.

Hanahan, D. (1983). Studies on transformation of Escherichia coli with plasmids. J Mol Biol 166, 557-580.

Harris, R. M., Webb, D. C., Howitt, S. M. \& Cox, G. B. (2001). Characterization of PitA and PitB from Escherichia coli. J Bacteriol 183, 5008-5014.

Hidalgo, E. \& Demple, B. (1997). Spacing of promoter elements regulates the basal expression of the soxS gene and converts SoxR from a transcriptional activator into a repressor. EMBO J 16, 10561065 .

Higgens, C. E., Hamill, R. L., Sands, T. H., Hoehn, M. M. \& Davis, N. E. (1974). Letter: the occurrence of deacetoxycephalosporin $C$ in fungi and streptomycetes. J Antibiot (Tokyo) 27, 298-300.

Hoffer, S. M., Schoondermark, P., van Veen, H. W. \& Tommassen, J. (2001). Activation by gene amplification of pitB, encoding a third phosphate transporter of Escherichia coli K-12. J Bacteriol 183, 4659-4663.
Hofmann, K. \& Stoffel, W. (1993). TMbase: a database of membrane spanning proteins segments. Biol Chem Hoppe Seyler 374, 166.

Ikeda, H., Ishikawa, J., Hanamoto, A., Shinose, M., Kikuchi, H., Shiba, T., Sakaki, Y., Hattori, M. \& Omura, S. (2003). Complete genome sequence and comparative analysis of the industrial microorganism Streptomyces avermitilis. Nat Biotechnol 21, 526-531.

Kanehisa, M., Goto, S., Hattori, M., Aoki-Kinoshita, K. F., Itoh, M., Kawashima, S., Katayama, T., Araki, M. \& Hirakawa, M. (2006). From genomics to chemical genomics: new developments in KEGG. Nucleic Acids Res 34 ((database issue)), D354-D357.

Keasling, J. D. (1997). Regulation of intracellular toxic metals and other cations by hydrolysis of polyphosphate. Ann N Y Acad Sci 829, 242-249.

Kieser, T., Bibb, M. J., Buttner, M. J., Chater, K. F. \& Hopwood, D. A. (2000). Practical Streptomyces Genetics. Norwich, UK: The John Innes Foundation.

Lanzetta, P. A., Álvarez, L. J., Reinach, P. S. \& Candia, O. A. (1979). Improved assay for nanomole amounts of inorganic phosphate. Anal Biochem 100, 95-97.

Liu, W., Qi, Y. \& Hulett, F. M. (1998). Sites internal to the coding regions of $p h o A$ and $p s t S$ bind $\mathrm{PhoP}$ and are required for full promoter activity. Mol Microbiol 28, 119-130.

MacNeil, D. J., Gewain, K. M., Ruby, C. L., Dezeny, G., Gibbons, P. H. \& MacNeil, T. (1992). Analysis of Streptomyces avermitilis genes required for avermectin biosynthesis utilizing a novel integration vector. Gene 111, 61-68.

Makarewicz, O., Dubrac, S., Msadek, T. \& Borriss, R. (2006). Dual role of the PhoP-P response regulator: Bacillus amyloliquefaciens FZB45 phytase gene transcription is directed by positive and negative interactions with the phyC promoter. J Bacteriol 188, 6953-6965.

Marcos, A. T., Gutirrrez, S., Diez, B., Fernfindez, F. J., Oguiza, J. A. \& Martin, J. F. (1995). Three genes $h r d B, h r d D$ and $h r d T$ of Streptomyces griseus IMRU 3570, encoding sigma factor-like proteins, are differentially expressed under specific nutritional conditions. Gene 153, 41-48.

Martín, J. F. \& Demain, A. L. (1977). Cleavage of adenosine 5'monophosphate during uptake by Streptomyces griseus. J Bacteriol 132, 590-595.

Martín, J. F. \& Demain, A. L. (1980). Control of antibiotic synthesis. Microbiol Rev 44, 230-251.

Martín, J. F., Marcos, A. T., Martín, A., Asturias, J. A. \& Liras, P. (1994). Phosphate control of antibiotic biosynthesis at the transcriptional level. In Phosphate in Microorganisms: Cellular and Molecular Biology, pp. 140-147. Edited by A. Torriani-Gorini, E. Yagil \& S. Silver. Washington, DC: American Society for Microbiology.

Mendes, M. V., Tunca, S., Antón, N., Recio, E., Sola-Landa, A., Aparicio, J. F. \& Martín, J. F. (2007). The two-component phoR-phoP system of Streptomyces natalensis: Inactivation or deletion of phoP reduces the negative phosphate regulation of pimaricin biosynthesis. Metab Eng 9, 217-227.

Minnig, K., Lazarevic, V., Soldo, B. \& Mauël, C. (2005). Analysis of teichoic acid biosynthesis regulation reveals that the extracytoplasmic function sigma factor $\sigma^{\mathrm{M}}$ is induced by phosphate depletion in Bacillus subtilis W23. Microbiology 151, 3041-3049.

Nikata, T., Sakai, Y., Shibat, K., Kato, J., Kuroda, A. \& Ohtake, H. (1996). Molecular analysis of the phosphate-specific transport (pst) operon of Pseudomonas aeruginosa. Mol Gen Genet 250, 692-698.

Omura, S., Ikeda, H., Ishikawa, J., Hanamoto, A., Takahashi, C., Shinose, M., Takahashi, Y., Horikawa, H., Nakazawa, H. \& other authors (2001). Genome sequence of an industrial microorganism Streptomyces avermitilis: deducing the ability of producing secondary metabolites. Proc Natl Acad Sci U S A 98, 12215-12220. 
Paul, S., Birkey, S., Liu, W. \& Hulett, F. M. (2004). Autoinduction of Bacillus subtilis phoPR operon transcription results from enhanced transcription from $\mathrm{E} \sigma^{\mathrm{A}}-$ and $\mathrm{E} \sigma^{\mathrm{E}}$-responsive promoters by phosphorylated PhoP. J Bacteriol 186, 4262-4275.

Rao, N. N. \& Torriani, A. (1990). Molecular aspects of phosphate transport in Escherichia coli. Mol Microbiol 4, 1083-1090.

Rice, P., Longden, I. \& Bleasby, A. (2000). EMBOSS: the European Molecular Biology Open Software Suite. Trends Genet 16, 276-277.

Rodríguez-García, A., Ludovice, M., Martín, J. F. \& Liras, P. (1997). Arginine boxes and the $\arg R$ gene in Streptomyces clavuligerus: evidence for a clear regulation of the arginine pathway. Mol Microbiol 25, 219-228.

Rodríguez-Garcia, A., Barreiro, C., Santos-Beneit, F., Sola-Landa, A. \& Martín, J. F. (2007). Genome-wide transcriptomic and proteomic analysis of the primary response to phosphate limitation in Streptomyces coelicolor M145 and in a $\Delta p h o P$ mutant. Proteomics 7, 2410-2429.

Rosenberg, H., Gerdes, R. G. \& Chegwidden, K. (1977). Two systems for the uptake of phosphate in Escherichia coli. J Bacteriol 131, 505-511.

Rosenberg, H., Gerdes, R. G. \& Harold, F. M. (1979). Energy coupling to the transport of inorganic phosphate in Escherichia coli K12. Biochem J 178, 133-137.

Russell, L. M. \& Rosenberg, H. (1980). The nature of the link between potassium transport and phosphate transport in Escherichia coli. Biochem J 188, 715-723.

Saier, M. H., Jr, Eng, B. H., Fard, S., Garg, J., Haggerty, D. A., Hutchinson, W. J., Jack, D. L., Lai, E. C., Liu, H. J. \& other authors (1999). Phylogenetic characterization of novel transport protein families revealed by genome analyses. Biochim Biophys Acta 1422, $1-56$.

Sambrook, J., Fritsch, E. F. \& Maniatis, T. (1989). Molecular Cloning: a Laboratory Manual, 2nd edn. Cold Spring Harbor, NY: Cold Spring Harbor Laboratory.

Schaaf, S. \& Bott, M. (2007). Target genes and DNA-binding sites of the response regulator PhoR from Corynebacterium glutamicum. J Bacteriol 189, 5002-5011.

Schneider, T. D. (1996). Reading of DNA sequence logos: prediction of major groove binding by information theory. Methods Enzymol 274, 445-455.

Schneider, T. D. (1997). Sequence walkers: a graphical method to display how binding proteins interact with DNA or RNA sequences. Nucleic Acids Res 25, 4408-4415.

Schneider, T. D. \& Stephens, R. M. (1990). Sequence logos: a new way to display consensus sequences. Nucleic Acids Res 18, 6097-6100.

Sola-Landa, A., Moura, R. S. \& Martín, J. F. (2003). The twocomponent PhoR-PhoP system controls both primary metabolism and secondary metabolite biosynthesis in Streptomyces lividans. Proc Natl Acad Sci U S A 100, 6133-6138.
Sola-Landa, A., Rodríguez-Garcia, A., Franco-Dominguez, E. \& Martín, J. F. (2005). Binding of PhoP to promoters of phosphateregulated genes in Streptomyces coelicolor: identification of $\mathrm{PHO}$ boxes. Mol Microbiol 56, 1373-1385.

Sola-Landa, A., Rodríguez-Garcia, A., Apel, A. K. \& Martín, J. F. (2008). Target genes and structure of the direct repeats in the DNAbinding sequences of the response regulator PhoP in Streptomyces coelicolor. Nucleic Acids Res 36, 1358-1368.

Strohl, W. R. (1992). Compilation and analysis of DNA sequences associated with apparent streptomycete promoters. Nucleic Acids Res 20, 961-974.

van Veen, H. W. (1997). Phosphate transport in prokaryotes: molecules, mediators and mechanisms. Antonie Van Leeuwenhoek 72, 299-315.

van Veen, H. W., Abee, T., Kortstee, G. J., Konings, W. N. \& Zehnder, A. J. (1993). Characterization of two phosphate transport systems in Acinetobacter johnsonii 210A. J Bacteriol 175, 200-206.

van Veen, H. W., Abee, T., Kortstee, G. J., Konings, W. N. \& Zehnder, A. J. (1994a). Translocation of metal phosphate via the phosphate inorganic transport system of Escherichia coli. Biochemistry 33, 17661770 .

van Veen, H. W., Abee, T., Kortstee, G. J., Konings, W. N. \& Zehnder, A. J. (1994b). Substrate specificity of the two phosphate transport systems of Acinetobacter johnsonii 210A in relation to phosphate speciation in its aquatic environment. J Biol Chem 269, 16212-16216.

van Veen, H. W., Abee, T., Kortstee, G. J., Pereira, H., Konings, W. N. \& Zehnder, A. J. (1994c). Generation of a proton motive force by the excretion of metal-phosphate in the polyphosphate-accumulating Acinetobacter johnsonii strain 210A. J Biol Chem 269, 29509-29514.

Voegele, R. T., Bardin, S. \& Finan, T. M. (1997). Characterization of the Rhizobium (Sinorhizobium) meliloti high- and low-affinity phosphate uptake systems. J Bacteriol 179, 7226-7232.

von Mering, C., Jensen, L. J., Kuhn, M., Chaffron, S., Doerks, T., Kruger, B., Snel, B. \& Bork, P. (2007). STRING 7 - recent developments in the integration and prediction of protein interactions. Nucleic Acids Res 35 (database issue), D358-D362.

Whitworth, D. E., Holmes, A. B., Irvine, A. G., Hodgson, D. A. \& Scanlan, D. J. (2008). Phosphate acquisition components of the Myxococcus xanthus Pho regulon are regulated by both phosphate availability and development. J Bacteriol 190, 1997-2003.

Yuan, Z. C., Zaheer, R. \& Finan, T. M. (2006a). Regulation and properties of PstSCAB, a high-affinity, high-velocity phosphate transport system of Sinorhizobium meliloti. J Bacteriol 188, 1089-1102.

Yuan, Z. C., Zaheer, R., Morton, R. \& Finan, T. M. (2006b). Genome prediction of PhoB regulated promoters in Sinorhizobium meliloti and twelve proteobacteria. Nucleic Acids Res 34, 2686-2697.

Edited by: J.-H. Roe 